\title{
Ärztinnen und Ärzte fürs Parlament
}

27 Ärzte und 2 Ärztinnen, die im Herbst für die Parlamentswahlen kandidieren werden, sind unserem Aufruf gefolgt und haben einen kurzen Steckbrief zur ihrer Person und ihren politischen Anliegen geschickt (siehe Seiten 1838-48).

Diese Kollegen kandidieren für 8 verschiedene Parteien aus 13 Kantonen. Besonders stark vertreten sind der Kanton Waadt mit 8 und der Kanton Zürich mit 7 Kandidaten.

Von den Parteien ist die FDP mit 9 Kandidaten am stärksten vertreten, gefolgt von der CVP und der PdA/POP mit je 4 Kandidaten. SP, EVP und Grüne stellen je 2 Kandidaten. Ein Arzt kandidiert für die Schweizer Demokraten.

Unter den Kandidaten finden sich 10 Allgemeinpraktiker, 3 Chirurgen, 3 Sozial- und Präventivmediziner und 3 Psychiater; 6 haben einen anderen und 4 keinen Facharzttitel.

Die Kolleginnen sind im Durchschnitt 52 Jahre alt (Median 52, Min. 24, Max. 73).

Die kandidierenden Ärztinnen und Ärzte sind zahlreich, was erfreulich ist. Sie vertreten zudem ein breites parteipolitisches Spektrum, was ebenfalls erfreulich ist, jedoch keine grosse Überraschung darstellt. Längst vorbei ist die Zeit, als sich Ärzte um das politische Geschehen nicht zu kümmern brauchten. Vorbei ist wohl auch die Zeit - so es eine solche überhaupt gegeben hat -, als sich die Ärzteschaft einer bestimmten Partei zuordnen liess. Wie wir das von den Beiträgen in der SÄZ gewohnt sind, kommen auch in den hier publizierten Steckbriefen sehr heterogene, z. T. entgegengesetzte Ansichten zur Gesundheitsund Berufspolitik zum Ausdruck. «2 Ärzte, 3 Meinungen» gilt wahrlich nicht nur für medizinische Angelegenheiten ...

Auch wenn diese Kandidaten keine repräsentative Stichprobe der Ärzteschaft darstellen, so kann man sich dennoch des Eindrucks nicht erwehren, dass diese politisch erwacht ist. Gründe, keine passive Rolle mehr spielen zu wollen, hätte sie jedenfalls zur Genüge.

Bei dieser Gelegenheit drängt sich die Frage auf, wie innerhalb der FMH mit diesen verschiedenen politischen Tendenzen umzugehen sei. Die heutigen Strukturen der FMH sind bestens geeignet, eine klassische Politik der Besitzstandswahrung $\mathrm{zu}$ betreiben. Ginge es aber darum, einen Wettbewerb von Ideen und Programmen auszutragen, was bei offenkundigen politischen Meinungsverschiedenheiten nicht nur legitim, sondern auch wünschenswert wäre, wären die dafür in Frage kommenden Gremien mit erheblichen, wenn nicht sogar unüberwindlichen Schwierigkeiten konfrontiert. Diesen Schwierigkeiten aus dem Weg zu gehen und den Konsens durch einstimmiges Schweigen zu suchen, dürfte auf lange Sicht keine befriedigende Antwort sein. Die Frage bleibt, was die FMH betrifft, vorderhand ungeklärt.

Immerhin kann ich als Bürger politischen Einfluss nehmen: wählen gehen!

Markus Trutmann 